(2) OPEN ACCESS

\title{
TNF- $\alpha$ inhibitors used as steroid-sparing maintenance monotherapy in parenchymal CNS sarcoidosis
}

\author{
Frédéric Hilezian @ (1) ${ }^{1}$ Adil Maarouf, ${ }^{1,2}$ Clemence Boutiere, ${ }^{1,2}$ Audrey Rico, ${ }^{1,2}$ \\ Sarah Demortiere (10, ${ }^{1,2}$ Philippe Kerschen, ${ }^{3}$ Thomas Sene, ${ }^{4}$ Caroline Bensa-Koscher, ${ }^{5}$ \\ Claire Giannesini, ${ }^{6,7}$ Jean Capron, ${ }^{6,7}$ Arsene Mekinian, ${ }^{7,8}$ \\ Jean-Philippe Camdessanché (1), ${ }^{9}$ Géraldine Androdias, ${ }^{10}$ Romain Marignier, ${ }^{11,12}$ \\ Nicolas Collongues (1) ${ }_{13,14}^{13}$ Olivier Casez ${ }_{1}^{15}$ Catalina Coclitu, ${ }_{1}^{15}$ Mathieu Vaillant, ${ }_{1}^{15}$ \\ Guillaume Mathey 주, ${ }^{16,17}$ Jonathan Ciron, ${ }^{18}$ Jean Pelletier, ${ }^{1,2}$ Bertrand Audoin, ${ }^{1,2}$ \\ Under the aegis of the French Multiple Sclerosis Society
}

For numbered affiliations see end of article.

\section{Correspondence to}

Professor Bertrand Audoin, Hôpital de la Timone, Pôle de Neurosciences Cliniques, Service de Neurologie, 13005, Assistance Publique Hopitaux de Marseille, Marseille, ProvenceAlpes-Côte d'Azur, France; bertrand.audoin@ap-hm.fr

Received 28 November 2020 Revised 12 April 2021

Accepted 14 April 2021 Published Online First 8 June 2021

\section{SLinked}

- http://dx.doi.org/10.1136/ jnnp-2021-326267

Check for updates

(C) Author(s) (or their employer(s)) 2021. Re-use permitted under CC BY-NC. No commercial re-use. See rights and permissions. Published by BMJ.

To cite: Hilezian F, Maarouf A, Boutiere C, et al. J Neurol Neurosurg Psychiatry

2021:92:890-896.

\section{ABSTRACT}

Objective To assess the efficacy of tumour necrosis factor- $\alpha$ (TNF- $\alpha$ ) inhibitors used as steroid-sparing monotherapy in central nervous system (CNS) parenchymal sarcoidosis.

Methods The French Multiple Sclerosis and Neuroinflammation Centers retrospectively identified patients with definite or probable CNS sarcoidosis treated with TNF- $\alpha$ inhibitors as steroid-sparing monotherapy. Only patients with CNS parenchymal involvement demonstrated by MRI and imaging follow-up were included. The primary outcome was the minimum dose of steroids reached that was not associated with clinical or imaging worsening during a minimum of 3 months after dosing change.

Results Of the identified 38 patients with CNS sarcoidosis treated with TNF- $\alpha$ inhibitors, 23 fulfilled all criteria (13 females). Treatments were infliximab $(n=22)$ or adalimumab $(n=1)$ for a median (IQR) of 24 (17-40) months. At treatment initiation, the mean (SD) age was $41.5(10.5)$ years and median (IQR) disease duration 22 (14-49.5) months. Overall, $60 \%$ of patients received other immunosuppressive agents before a TNF- $\alpha$ inhibitor. The mean (SD) minimum dose of steroids was 31.5 (33) mg before TNF- $\alpha$ inhibitor initiation and 6.5 (5.5) mg after ( $p=0.001$ ). In all, $65 \%$ of patients achieved steroids dosing $<6 \mathrm{mg} / \mathrm{day} ; 61 \%$ showed clinical improvement, $30 \%$ stability and $9 \%$ disease worsening. Imaging revealed improvement in $74 \%$ of patients and stability in $26 \%$.

Conclusion TNF- $\alpha$ inhibitors can greatly reduce steroids dosing in patients with CNS parenchymal sarcoidosis, even refractory.

Classification of evidence This study provides Class IV evidence that TNF- $\alpha$ inhibitor used as steroidsparing monotherapy is effective for patients with CNS parenchymal sarcoidosis.

\section{INTRODUCTION}

Sarcoidosis is a multisystem granulomatous disorder that most often affects the lungs, eyes and skin. ${ }^{12}$ Its incidence is highly variable across countries and ethnicities, ranging from 1 to 40 cases per 100000 people. ${ }^{12}$ Neurological involvement occurs in about
$5 \%$ of patients ${ }^{3}{ }^{4}$ and may be inaugural in $70 \% .^{5}$ Cranial nerve involvement and particularly facial palsy are the most common manifestations and occur in $70 \%$ of cases. ${ }^{3}$ Aseptic meningitis is the second most common manifestation. The central nervous system (CNS) parenchymal form is less common but is associated with worse prognosis. ${ }^{5}$

Treatment strategies for neurosarcoidosis are mainly based on expert opinion and small retrospective studies because the disorder is extremely rare. $^{6}$ For CNS sarcoidosis, the first-line therapy is steroids. However, the therapy response is frequently incomplete and associated with frequent side effects, which motivates the use of steroidsparing agents. Several agents, such as methotrexate, mycophenolate mofetil, cyclophosphamide and azathioprine, have been used in CNS sarcoidosis and could be partially efficient. More recently, monoclonal antibodies against tumour necrosis factor- $\alpha$ (TNF- $\alpha$ ) have been proposed: several studies have highlighted the involvement of TNF- $\alpha$ in the pathogenesis of sarcoidosis. ${ }^{7-10}$ Also, several case series have suggested the potential high efficacy of monoclonal antibodies against TNF- $\alpha$ in neurosarcoidosis. ${ }^{11-19}$ Because most patients included in these studies received a TNF- $\alpha$ inhibitor combined with other immunosuppressive agents, the potential efficacy of TNF- $\alpha$ inhibitors used as monotherapy for steroid sparing is largely unknown. Moreover, these studies included both patients with CNS parenchymal sarcoidosis and with isolated cranial nerves or aseptic meningitis known to have better prognosis than the parenchymal form. Thus, data are lacking on the potential efficacy of TNF- $\alpha$ inhibitors used as monotherapy for parenchymal CNS sarcoidosis.

In the present nationwide case series study including most of the French tertiary care Multiple Sclerosis and Neuroinflammation centres, we aimed to describe the evolution of parenchymal CNS sarcoidosis treated with TNF- $\alpha$ inhibitors as steroid-sparing monotherapy. To improve the reliability of the outcome measures, we included only patients with CNS MRI performed before and after TNF- $\alpha$ inhibitor initiation. 


\section{METHODS}

\section{Protocol and participants}

The project aimed to assess the clinical and MRI evolution of patients with a parenchymal form of CNS sarcoidosis treated with a TNF- $\alpha$ inhibitor used as monotherapy in the French Multiple Sclerosis and Neuroinflammation centres. The project was presented, discussed and initiated at the annual meeting of the French Multiple Sclerosis Society in September 2019, at which all French Multiple Sclerosis and Neuroinflammation centres were represented. Inclusion criteria were (1) diagnosis of probable or confirmed CNS sarcoidosis according to the consensus diagnostic criteria for neurosarcoidosis ${ }^{20}$; (2) parenchymal CNS lesion attributed to sarcoidosis demonstrated by MRI; (3) treatment with a TNF- $\alpha$ inhibitor and (4) at least 6 months' follow-up after TNF- $\alpha$ inhibitor initiation. Exclusion criteria were (1) no CNS MRI in the 12 months preceding the TNF- $\alpha$ inhibitor initiation; (2) no available MRI data after TNF- $\alpha$ inhibitor initiation and (3) the association of a TNF- $\alpha$ inhibitor and other steroidsparing maintenance immunotherapy.

\section{Outcomes}

The primary outcome was the minimum dose of steroids (MDS) (converted to equivalent doses of prednisolone) reached that was not associated with any clinical or MRI-evidenced worsening of CNS sarcoidosis during a minimum of 3 months after dosing change. These minimum doses of steroids were compared between before TNF- $\alpha$ inhibitor initiation (if applicable) and after. The secondary outcome was the proportion of patients with clinical and/or MRI-evidenced CNS sarcoidosis activity after TNF- $\alpha$ inhibitor initiation. Activity was defined as clinical worsening or progression of MRI-evidenced lesions compared with previous imaging. All MRI data available before and after TNF- $\alpha$ inhibitor initiation were collected. Worsening, stabilisation or improvement of CNS lesion(s) were assessed on each MRI image and compared with the previous image. For the sake of readability, each MRI was numbered with reference to the MRI performed just before TNF- $\alpha$ inhibitor initiation, arbitrarily named $\mathrm{MRI}_{0}$. MRI +1 was the first MRI performed after the TNF- $\alpha$ inhibitor initiation, $\mathrm{MRI}_{+2}$ the second, etc. $\mathrm{MRI}_{-1}$ was the MRI performed before $\mathrm{MRI}_{0}, \mathrm{MRI}_{-2}$ the MRI performed before $\mathrm{MRI}_{-1}$, etc. According to inclusion criteria, $\mathrm{MRI}_{0}$ and $\mathrm{MRI}_{+1}$ were available for all patients.

All adverse events (AEs) $\geq$ grade 2 according to the Common Terminology Criteria for Adverse Events (CTCAE) V.5.0 after TNF- $\alpha$ inhibitor initiation mentioned in the medical record were registered.

MRI changes were evaluated by the neurologist of each neuroinflammatory centre in charge of the patient. MRI improvement or worsening was defined as a reduction or increase in the extent of T2 abnormalities and/or gadolinium enhancement compared with the last MRI.

\section{Data availability}

The corresponding author has full access to all the data in the study. He takes full responsibility for the integrity of the data, the accuracy of the data analysis and interpretation, and the conduct of the research. The authors have the right to publish any and all data, separate and apart from the guidance of any sponsor.

\section{Statistical analyses}

Statistical analyses were performed with JMP V.9.0.0 (SAS Institute). Potential changes of the MDS between pre-TNF- $\alpha$ and post-TNF- $\alpha$ inhibitor periods were assessed with a Wilcoxon
Patients with neurosarcoidosis treated with TNF- $\alpha$ inhibitor used as steroid-sparing monotherapy identified by the French Multiple Sclerosis and Neuroinflammation Centers $(n=38)$

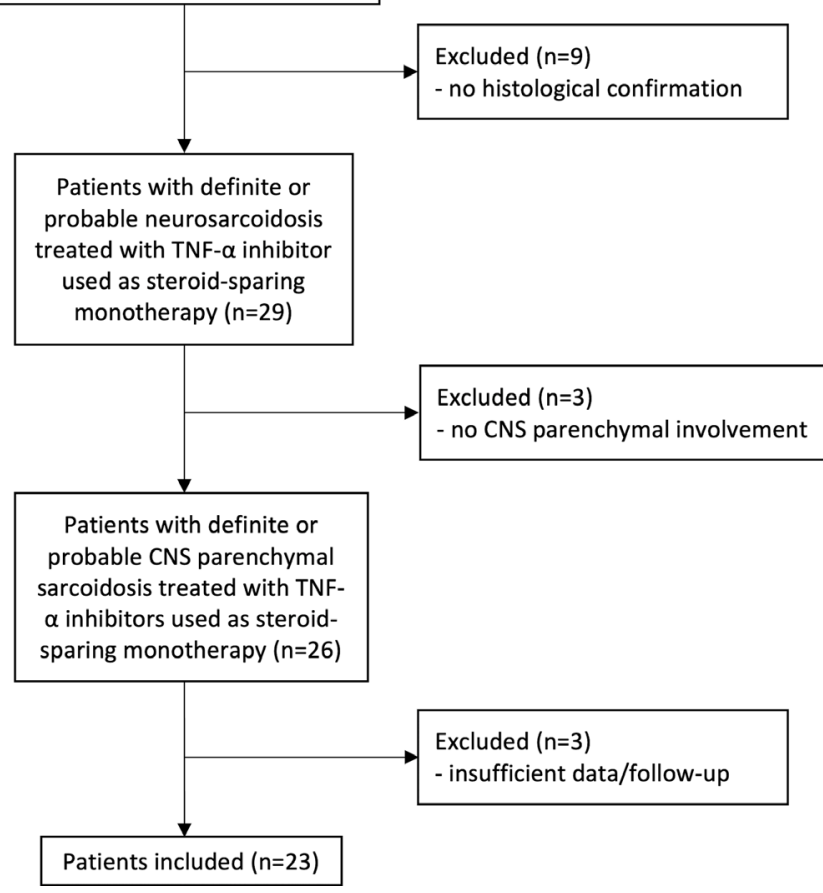

Figure 1 Flow chart of the study. CNS, central nervous system; TNF- $\alpha$, tumour necrosis factor- $\alpha$

signed-rank test with continuity correction. Potential changes in the proportion of patients with CNS sarcoidosis activity after TNF- $\alpha$ inhibitor initiation were assessed with the Cochran q test.

\section{RESULTS}

\section{Study population}

In total, 56 patients with parenchymal CNS sarcoidosis were identified in most of the French Multiple Sclerosis and Neuroinflammation centres: 38 received a TNF- $\alpha$ inhibitor. In these centres, the mean ratio of patients with CNS parenchymal sarcoidosis to those with multiple sclerosis ranged from $1 / 100$ to $1 / 150$.

After excluding patients not fulfilling all inclusion and exclusion criteria, 23 patients were included in the analysis (figure 1). Demographic, clinical and MRI characteristics of patients are in table 1 . The median (IQR) time between diagnosis and TNF- $\alpha$ inhibitor initiation was 22 months (14-49.5). The median (IQR) follow-up after TNF- $\alpha$ inhibitor initiation was 24 months (17-40). A total of 22 patients received infliximab $(5-10 \mathrm{mg} / \mathrm{kg}$ every $4-10$ weeks, most commonly $5 \mathrm{mg} / \mathrm{kg}$ every 8 weeks) and 1 adalimumab (40 mg every 2 weeks).

Before TNF- $\alpha$ inhibitor treatment, 9 of 23 patients fulfilled criteria of refractory parenchymal CNS sarcoidosis, defined as persistence of clinical and/or MRI activity after at least 6 months of immunosuppressive maintenance therapy or the need to use at least $20 \mathrm{mg} /$ day of steroids associated with immunosuppressive maintenance therapy to be stable. Before TNF- $\alpha$ inhibitor treatment, 15 of the 23 patients presented steroid dependency, 


\begin{tabular}{|c|c|}
\hline \multicolumn{2}{|l|}{ Neurosarcoidosis diagnosis, $\mathrm{n}(\%)$} \\
\hline Probable & $21(91.3)$ \\
\hline Definite & $2(8.7)$ \\
\hline Age at TNF- $\alpha$ inhibitor initiation, years, mean (SD) & $41.5(10.4)$ \\
\hline Sex ratio (M/F) & $10 / 13$ \\
\hline $\begin{array}{l}\text { Time between diagnosis and TNF- } \alpha \text { inhibitor initiation, months, } \\
\text { median (IQR) }\end{array}$ & $22(14-49.5)$ \\
\hline Time of TNF- $\alpha$ inhibitor exposure, months, median (IQR) & $24(17-40)$ \\
\hline \multicolumn{2}{|l|}{ Location of parenchymal CNS lesion(s), no of patients (\%) } \\
\hline Isolated cerebral involvement & $8(34.8)$ \\
\hline Isolated spinal cord involvement & $5(21.7)$ \\
\hline Isolated pituitary/hypothalamic involvement & $3(13)$ \\
\hline Mixed & $7(30.4)$ \\
\hline \multicolumn{2}{|l|}{ Type of TNF- $\alpha$ inhibitor used, no of patients (\%) } \\
\hline Infliximab & $22(95.7)$ \\
\hline Adalinumab & $1(4.3)$ \\
\hline \multicolumn{2}{|l|}{ Treatments used just before TNF- $\alpha$ inhibitor, no of patients (\%) } \\
\hline Corticosteroids & $23(100)$ \\
\hline Methotrexate & $8(34.8)$ \\
\hline Cyclophosphamide & $4(17.4)$ \\
\hline Azathioprine & $2(8.7)$ \\
\hline
\end{tabular}

CNS, central nervous system; TNF- $\alpha$, tumour necrosis factor- $\alpha$.

defined as a return to clinical and/or MRI activity during dosing reduction of steroids.

For the 14 patients who previously received immunosuppressive therapy, the median (IQR) duration of the switch between previous immunosuppressive therapy and TNF- $\alpha$ inhibitor treatment was 0.5 months $(0-2)$.

Overall, 22 of the 23 patients received infliximab and 1 patient adalimumab. The neurological history of this patient started at 36 years of age and was characterised by inflammatory lesions located in the spinal cord, the hypophysohypothalamic region and the fornix. CT scan demonstrated signs of sarcoidosis in the lung and adenopathies in the neck. The diagnosis of sarcoidosis was confirmed by a biopsy of one adenopathy. The patient received steroids and cyclophosphamide between February 2017 and April 2018. Steroids were progressively tapered, but dosing $<25 \mathrm{mg} /$ day was never reached. Adalimumab $40 \mathrm{mg}$ every 2 weeks was initiated in May 2018. MRI findings remained stable-T2 abnormalities without any gadolinium enhancement-and clinical improvement occurred despite progressive steroids tapering. At the last MRI in June 2019, the steroids dosing was $7.5 \mathrm{mg} /$ day (figure 1 , table 1 ).

\section{Outcomes measures}

MDS before and after TNF- $\alpha$ inhibitor initiation

The mean (SD) MDS reached (converted to equivalent doses of prednisolone) that was not associated with any clinical or MRI-evidenced worsening of CNS parenchymal sarcoidosis during a minimum of 3 months after dosing change was 31.5 (33) $\mathrm{mg}$ before TNF- $\alpha$ inhibitor initiation and 6.5 (5.5) $\mathrm{mg}$ after $(\mathrm{p}=0.001)$. After excluding patients without steroid tapering tentative before TNF- $\alpha$ inhibitor initiation $(n=7)$, the mean MDS was 14 (11.5) $\mathrm{mg}$ before and 5 (5) $\mathrm{mg}$ after $(p=0.0004)$. In the subgroup of patients treated with other steroid-sparing immunosuppressive agents before TNF- $\alpha$ inhibitor initiation $(n=14)$, the mean MDS was $18.5(16.5)$ $\mathrm{mg}$ before TNF- $\alpha$ inhibitor initiation and 5.5 (4.5) $\mathrm{mg}$ after $(p=0.002)$. In the subgroup of patients with refractory CNS parenchymal sarcoidosis $(n=9)$, the magnitude of TNF- $\alpha$ inhibitor efficacy was similar to that for other patients. The mean MDS in these patients was 23.7 (18.9) $\mathrm{mg} /$ day before TNF- $\alpha$ inhibitor treatment and 5.8 (5.9) $\mathrm{mg} /$ day after $(\mathrm{p}<0.005)$. After TNF- $\alpha$ inhibitor initiation, steroid doses were tapered, increased or unchanged in 21 (91\%), 1 (4\%) and $1(4 \%)$ of 23 patients, respectively. Steroids were successfully decreased to $<9 \mathrm{mg} /$ day for 18 of $23(78 \%)$ patients, $<6 \mathrm{mg}$ /day for 15 of $23(65 \%)$ and successfully stopped in 6 of $23(26 \%)$ patients. These dosing steroidequivalent cutoffs were chosen because $<9 \mathrm{mg}$ represents the cut-off at which side effects of steroids tend to disappear and $<6 \mathrm{mg}$ the cut-off at which the anti-inflammatory effect of steroids is not significant.

\section{Evolution of CNS parenchymal sarcoidosis after TNF- $\alpha$ inhibitor initiation}

\section{Evolution between TNF- $\alpha$ inhibitor initiation and last follow-up}

Just before TNF- $\alpha$ inhibitor initiation, at $\mathrm{MRI}_{0}$ (median 2 months before, IQR 2.5-1), the proportion of patients with clinical or MRI activity was $39 \%$ and the mean (SD) dose of steroids was 16.9 (22.5) $\mathrm{mg}$. At the last follow-up (median 24 months, IQR 17-40), the proportion of patients with clinical or MRI activity was $4 \%(p=0.005)$ and the mean dose of steroids was 6.4 (5.7) $\mathrm{mg}$. At the last follow-up, compared with treatment initiation, $61 \%$ of patients showed clinical improvement, 30\% clinical stability and 9\% worsening; $74 \%$ of patients showed a favourable outcome on MRI and 26\% stability.

Neutralising antibodies to infliximab were not measured in any patient because no patient was suspected to have worsened condition over time due to loss of efficacy of the TNF- $\alpha$ inhibitor. Only two patients showed worsened condition during TNF- $\alpha$ inhibitor treatment. The first patient was a middle-aged man presenting with a confuse state revealing an extensive frontal leptomeningitis and parenchymal involvement. Several months after the diagnosis of neurosarcoidosis and the onset of TNF- $\alpha$ inhibitor therapy, he presented epileptic seizures in a context of poor adherence to epileptic drugs whereas his brain MRI showed complete remission. The second patient was a middle-aged woman, presenting with tetraparesis, revealing an acute myelitis with meningeal enhancement. The diagnosis of neurosarcoidosis was done 2 years later, and TNF- $\alpha$ inhibitor therapy was started then. She presented no clinical improvement but a progressive walking impairment without any changes on spinal cord MRI. Muscular MRI showed proximal fatty involution of the lower limbs without oedema or gadolinium enhancement leading to a diagnosis of steroid myopathy.

Nine patients stopped TNF- $\alpha$ inhibitors: five due to a long period of stability and three for infection; one was lost to follow-up during 6 months. Follow-up data were available for seven of the nine patients: five demonstrated clinical and/or MRI worsening first diagnosed after a mean (SD) of 7.6 months (4) after stopping TNF- $\alpha$ inhibitors (figures 2-4).

\section{Dynamics of evolution after TNF- $\alpha$ inhibitor initiation}

$\mathrm{MRI}_{0}$ and $\mathrm{MRI}_{+1}$ data were available for all patients according

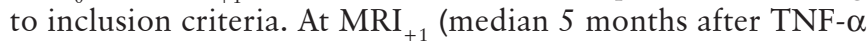
inhibitor initiation, IQR 3-9), the proportion of patients with clinical or MRI activity was $4 \%(\mathrm{p}=0.005$, compared with $\left.\mathrm{MRI}_{0}\right)$. MRI $\mathrm{M}_{+2}$ data were available for 17 patients: the proportion with clinical or MRI activity at $\mathrm{MRI}_{+2}$ (median 10.5 


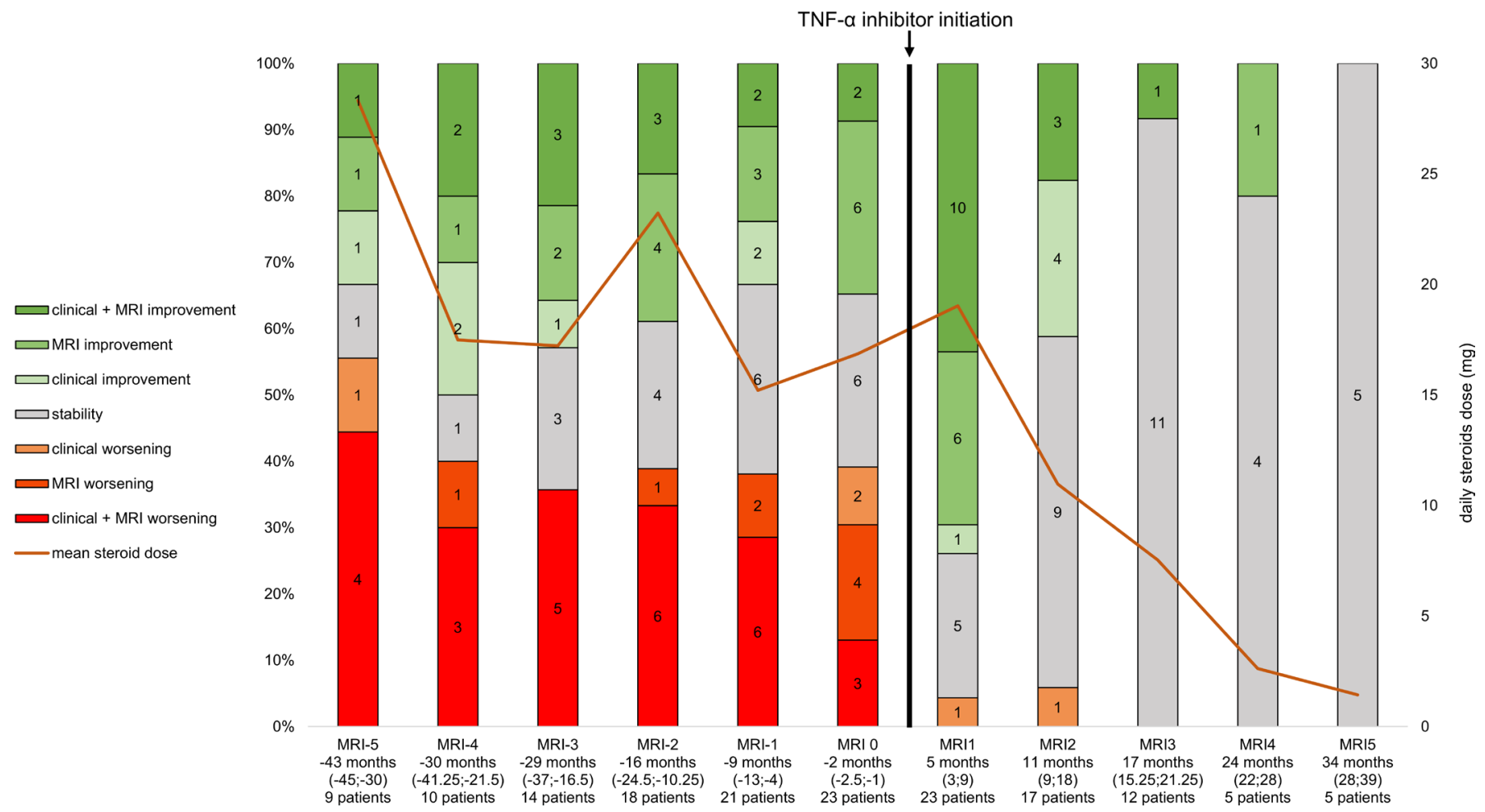

Figure 2 Dynamics of disease evolution before and after TNF- $\alpha$ inhibitor. TNF- $\alpha$, tumour necrosis factor- $\alpha$.

months after TNF- $\alpha$ inhibitor initiation, IQR 8.75-18.75) was $6 \%$ vs $35 \%$ at MRI $_{0}(\mathrm{p}=0.042)$. MRI $\mathrm{M}_{+3}$ data were available for 12 patients: the proportion with clinical or MRI activity at $\mathrm{MRI}_{+3}$ (median 17 months after TNF- $\alpha$ inhibitor initiation, IQR $15.25-21.25)$ was $0 \%$ vs $33 \%$ at $\mathrm{MRI}_{0}(\mathrm{p}=0.046)$. $\mathrm{MRI}_{+4}$ data were available for five patients: the proportion with clinical or MRI activity at $\mathrm{MRI}_{+4}$ (median 24 months after TNF- $\alpha$ inhibitor initiation, IQR $22-28$ ) was $0 \%$ vs $40 \%$ at $\mathrm{MRI}_{0}(\mathrm{p}=0.22) . \mathrm{MRI}_{+5}$ data were available for five patients: the proportion with clinical or MRI activity at $\mathrm{MRI}_{+5}$ (median 34 months after TNF- $\alpha$ inhibitor initiation, IQR 28-39) was $0 \%$ vs $40 \%$ at $\mathrm{MRI}_{0}(\mathrm{p}=0.22$ ) (figure 2 ).

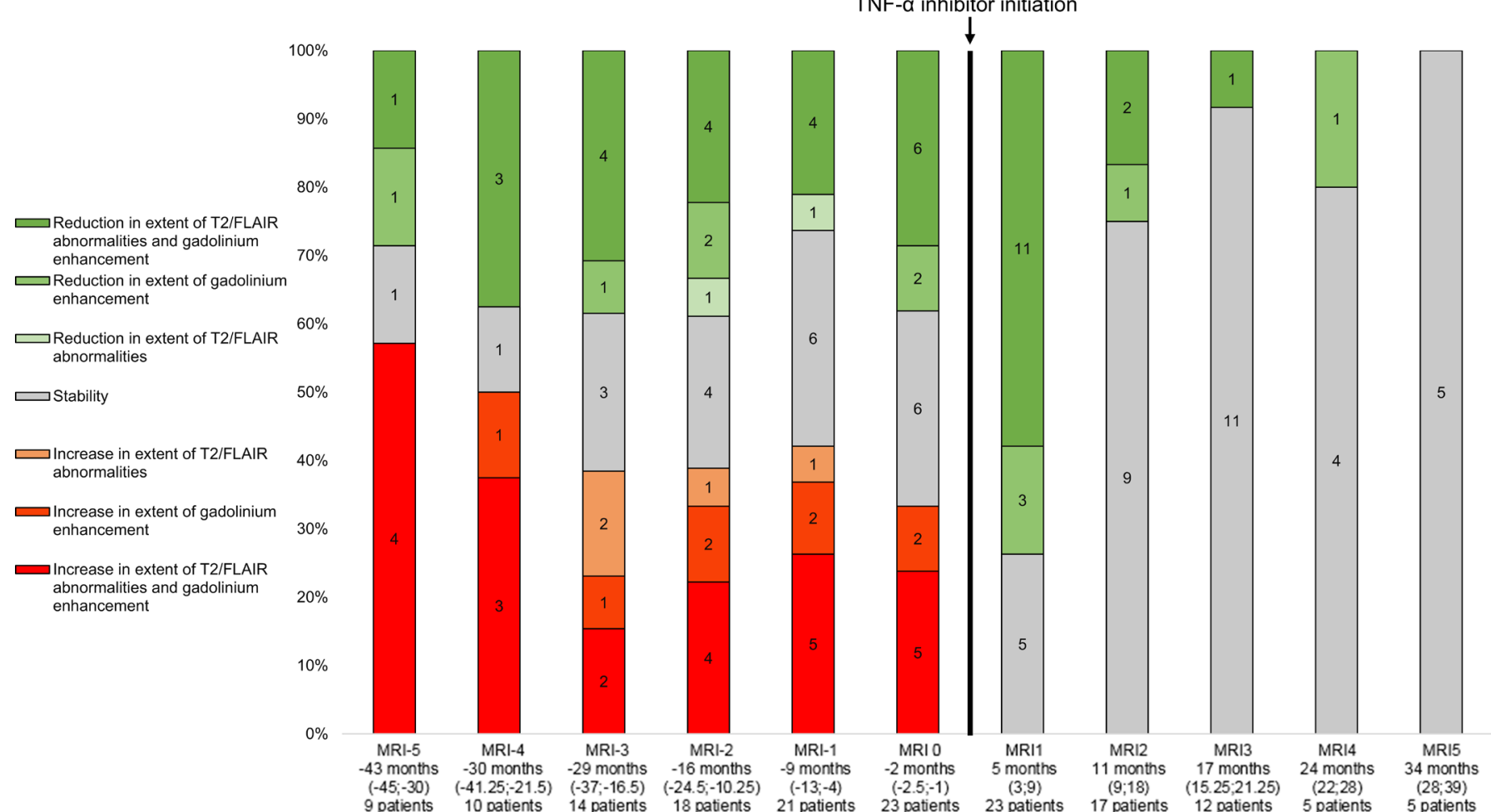

Figure 3 Characteristics of MRI evolution before and after TNF- $\alpha$ inhibitor. TNF- $\alpha$, tumour necrosis factor- $\alpha$. 


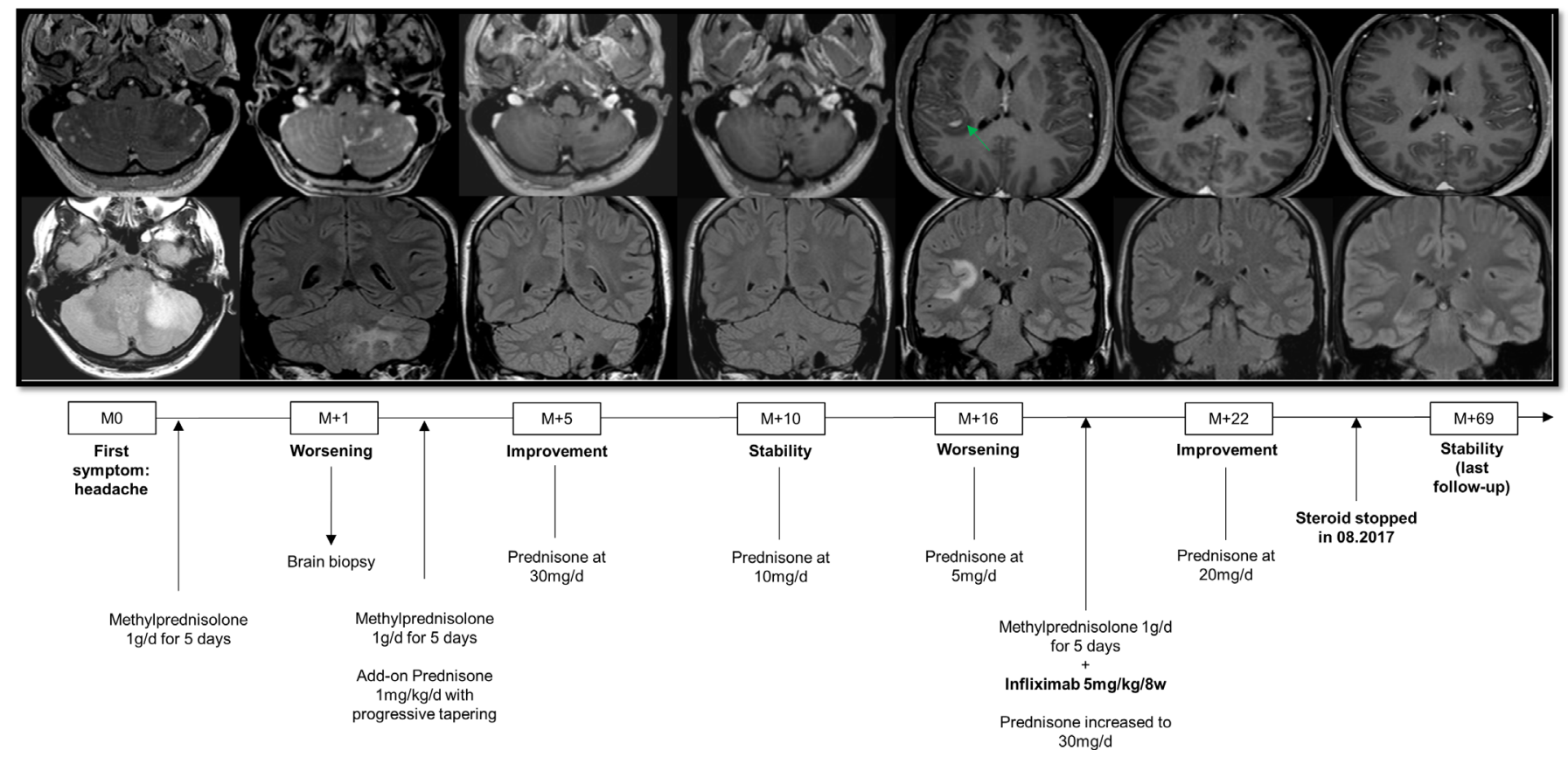

Figure 4 Complete stability and steroids withdrawn after TNF- $\alpha$ inhibitor initiation in a patient with an isolated cerebral sarcoidosis with previous disease worsening after steroids were tapered. TNF- $\alpha$, tumour necrosis factor- $\alpha$.

\section{Safety of TNF- $\alpha$ inhibitors}

In total, 10 AEs $\geq$ grade 2 of the CTCAE occurred in 10 patients. No patient died. Three AEs grade 3 and one AE grade 4 were reported. All AEs were related to infection: one diverticulitis (grade 2), two urinary infections (grade 2), two lower respiratory tract infections (one grade 3 and one grade 4), one dermatophytosis (grade 2), one isolated fever (grade 2), one hepatitis E (grade 3), one post-traumatic infection of a finger (grade 2) and one dermohypodermitis (grade 3 ).

\section{DISCUSSION}

The parenchymal form of CNS sarcoidosis is an extremely rare disorder with a potentially devastating prognosis. In the present French nationwide study, we report the evolution of CNS parenchymal sarcoidosis-mostly refractory-treated with a TNF- $\alpha$ inhibitor. We found fast and striking clinical and radiological improvement in most patients after treatment initiation. Importantly, improvement was evidenced when steroids had been tapered rapidly after treatment onset, reaching a dose $<9 \mathrm{mg}$ in most patients at the end of follow-up at a median of 24 months.

First-line treatment in neurosarcoidosis consists of glucocorticoids, usually oral prednisone. ${ }^{21}$ However, a large number of neurosarcoidosis cases are refractory to steroids or show relapse when dosing is tapered. ${ }^{22-24}$ In this case, second-line or steroidsparing immunosuppressive agents are indicated. ${ }^{6}$ Apart from TNF- $\alpha$ inhibitors, several second-line or steroid-sparing immunosuppressive agents used include methotrexate, azathioprine, cyclophosphamide and mycophenolate mofetil. Previous studies have reported that most patients with refractory neurosarcoidosis show improvement with these therapies, but a significant proportion show worsened disease or need greater steroid doses. $^{16222325-27}$

Likewise, we found that neurosarcoidosis was refractory to steroids and second-line therapies combined in many of our 23 patients before TNF- $\alpha$ inhibitor initiation. About $40 \%$ of our patients showed active disease despite a steroid dose $>15 \mathrm{mg} /$ day and second-line therapy in $60 \%$, including methotrexate, cyclophosphamide and azathioprine. This relatively large proportion of patients with refractory neurosarcoidosis is probably related to the characteristics of the patients recruited. All patients included had CNS parenchymal sarcoidosis; thus, patients with potential more benign forms of neurosarcoidosis such as isolated cranial nerve or isolated meningeal involvement were excluded. Only patients with the more severe form of neurosarcoidosis were included in the present study, but we observed substantial clinical and MRI-evidenced improvement after TNF- $\alpha$ inhibitor initiation. Crucially, improvement occurred while steroids were being tapered in 21 of 23 patients, and the mean dose of steroids decreased to $6.5 \mathrm{mg} /$ day. This favourable evolution despite marked reduction of steroids dosing strongly argues for the high efficacy of this treatment in CNS parenchymal sarcoidosis.

Of note, we included only patients receiving TNF- $\alpha$ inhibitors used as steroid-sparing monotherapy in the present study. This situation provides another argument for the potential high efficacy of TNF- $\alpha$ inhibitors in CNS parenchymal sarcoidosis. Indeed, the potential efficacy of TNF- $\alpha$ antagonists in CNS sarcoidosis has been suggested by several retrospective case series studies, but no study has assessed the potential efficacy when they are used as steroid-sparing monotherapy. In the largest study published, ${ }^{14}$ including 66 patients with CNS sarcoidosis treated with TNF- $\alpha$ inhibitors, 14 received a TNF- $\alpha$ inhibitor as monotherapy. The combination of steroidsparing agents was associated with better clinical outcomes than with TNF- $\alpha$ antagonists alone. However, this result was not confirmed when outcome measures included MRI. In the present study, only 2 of 23 patients showed disease worsening, which was characterised by clinical progression without any imaging changes. Thus, TNF- $\alpha$ inhibitor used as monotherapy may be efficient in neurosarcoidosis. Importantly, that good outcomes occur in patients with parenchymal involvement allows for more easily generalising the potential efficacy to all forms of CNS sarcoidosis. 
As reported in several studies of neurosarcoidosis, ${ }^{14} 19$ infections were encountered here in a significant number of patients receiving a TNF- $\alpha$ inhibitor. Ten infections including two serious infections occurred in 10 of 23 patients. No specific patterns of infection were evidenced. Finally, follow-up data were available for 7 of 9 patients who stopped TNF- $\alpha$ inhibitors: 5 experienced clinical and MRI worsening in the few months (mean 7.6) after stopping arguing for active surveillance of patients in case of treatment discontinuation.

The present study has some limitations. First, the sample size is small, inherent to the rarity of the disease and the stringent inclusion criteria. As mentioned above, the characteristics of the population were highly homogeneous, which allowed for describing the effect of TNF- $\alpha$ inhibitors in the most aggressive form of neurosarcoidosis. Second, we cannot fully exclude that regression to the mean effect partly contributes to the dramatic decrease of disease activity measured after TNF- $\alpha$ inhibitor. However, in the present study, in order to rule out a simple regression to the mean effect, we have collected the disease activity since the first MRI available in all the patients and evidenced in the large majority of the patients an important disease activity for several years and a clear breaking point in this disease activity since the onset of TNF- $\alpha$ inhibitor. Third, the follow-up was short, which may underestimate a potential medium-term return of disease activity or side effects. Fourth, the retrospective design may have contributed to underreporting side effects.

The present study suggests that TNF- $\alpha$ inhibitor treatment is associated with clinical and imaging improvement in patients with CNS parenchymal sarcoidosis and allows for tapering steroids to $<9 \mathrm{mg} /$ day in almost $80 \%$ of them. This study provides Class IV evidence that for patients with CNS parenchymal sarcoidosis, a TNF- $\alpha$ inhibitor used as monotherapy is effective for tapering steroids.

\author{
Author affiliations \\ 'Service de Neurologie, Hôpital de la Timone, Hôpitaux Universitaires de Marseille, \\ Marseille, France \\ ${ }^{2}$ Aix-Marseille Université, CNRS, CRMBM, Marseille, France, Marseille, France \\ ${ }^{3}$ Service de Neurologie, Centre Hospitalier de Luxembourg, Luxembourg-Ville, \\ Luxembourg \\ ${ }^{4}$ Service de Médecine Interne, Hôpital Rothschild, Paris, France \\ ${ }^{5}$ Service de Neurologie, Hôpital Rothschild, Paris, France \\ ${ }^{6}$ Service de Neurologie, Hôpital Saint-Antoine, AP-HP, Paris, France \\ ${ }^{7}$ Sorbonne Université, Paris, France \\ ${ }^{8}$ Service de Medecine Interne, Hôpital Saint-Antoine, AP-HP, Paris, France \\ ${ }^{9}$ Service de Neurologie, Hôpital Universitaire de Saint-Etienne, Saint-Etienne, France \\ ${ }^{10}$ Service de Neurologie, Sclérose en Plaques, Hospices Civils de Lyon, Hôpital \\ Neurologique Pierre Wertheimer, Lyon/Bron, France \\ ${ }^{11}$ Pathologies de la myéline et neuro-inflammation, et Centre de Référence des \\ Maladies Inflammatoires Rares du Cerveau et de la Moelle, Hôpital Neurologique \\ Pierre Wertheimer, Lyon/Bron, France \\ ${ }^{12}$ Université Claude Bernard Lyon 1, Lyon, France \\ ${ }^{13}$ Servie de Neurologie, Hôpital Universitaire de Strasbourg, Strasbourg, France \\ ${ }^{14}$ Centre d'investigation clinique, U1434, INSERM, Strasbourg, France \\ ${ }^{15}$ Clinique de Neurologie, Pathologies Inflammatoires du Système Nerveux, Hôpital \\ Universitaire Grenoble Alpes, Grenoble, France \\ ${ }^{16}$ Service de Neurologie, Hôpital Universitaire de Nancy, Nancy, France \\ ${ }^{17}$ APEMAC, EA 4360, Université de Lorraine, Nancy, France \\ ${ }^{18}$ Service de Neurologie, CRC-SEP, Hôpital Universitaire de Toulouse, Toulouse, France
}

Contributors BA initiated the study, planned and conducted the study, conducted statistical analysis and wrote the manuscript. AM played a major role in the acquisition of the data and in the formatting of the figures and revised the manuscript. FH played a major role in the acquisition of the data and the gathering the data. CB, AR, SD, PK, TS, CB-K, CG, JC, AM, J-PC, GA, RM, NC, OC, CC, MV, $G M, J C$ and JP played a major role in the acquisition of the data and revised the manuscript. As reported in the method section of the manuscript, all the authors listed have contributed to the conception of the present retrospective study. Indeed, the conception of the study has been deeply discussed between all the co-authors listed in a specific meeting during the annual meeting of the French Multiple Sclerosis Society in September 2019. Then, all the authors have participated to the draft and/or the revision of the paper and checked the accuracy or integrity of all aspects of the work. Finally, all the co-authors have approved the final version of the manuscript. In that way, we consider that all the names listed meet the ICMJE authorship requirements.

Funding The authors have not declared a specific grant for this research from any funding agency in the public, commercial or not-for-profit sectors.

\section{Competing interests None declared.}

\section{Patient consent for publication Not required.}

Ethics approval The authors obtained ethical approval of the institutional review board of the University Hospital of Marseille, France (number of the approval, RGPD/ AP-HM 2020-76) to conduct the present study based on retrospective chart review.

Provenance and peer review Not commissioned; externally peer reviewed.

Data availability statement Data are available upon reasonable request. The corresponding author has full access to all the data in the study. He takes full responsibility for the integrity of the data, the accuracy of the data analysis and interpretation, and the conduct of the research. The authors have the right to publish any and all data, separate and apart from the guidance of any sponsor. Individuals participant data underlying the results reported in this article will be available for the reviewers. Proposals should be directed to bertrand.audoin@ap-hm.fr for access to those data.

Open access This is an open access article distributed in accordance with the Creative Commons Attribution Non Commercial (CC BY-NC 4.0) license, which permits others to distribute, remix, adapt, build upon this work non-commercially, and license their derivative works on different terms, provided the original work is properly cited, appropriate credit is given, any changes made indicated, and the use is non-commercial. See: http://creativecommons.org/licenses/by-nc/4.0/.

\section{ORCID iDs}

Frédéric Hilezian http://orcid.org/0000-0002-5854-9325

Sarah Demortiere http://orcid.org/0000-0002-8513-5443

Jean-Philippe Camdessanché http://orcid.org/0000-0002-5282-6707

Nicolas Collongues http://orcid.org/0000-0002-3683-5582

Guillaume Mathey http://orcid.org/0000-0002-5747-9169

\section{REFERENCES}

1 lannuzzi MC, Rybicki BA, Teirstein AS. Sarcoidosis. N Engl J Med 2007;357:2153-65.

2 lannuzzi MC, Fontana JR. Sarcoidosis: clinical presentation, immunopathogenesis, and therapeutics. JAMA 2011:305:391-9.

3 Stern BJ, Krumholz A, Johns C, et al. Sarcoidosis and its neurological manifestations. Arch Neurol 1985:42:909-17.

4 Baughman RP, Teirstein AS, Judson MA, et al. Clinical characteristics of patients in a case control study of sarcoidosis. Am J Respir Crit Care Med 2001;164:1885-9.

5 Ferriby D, de Seze J, Stojkovic T, et al. Long-Term follow-up of neurosarcoidosis. Neurology 2001;57:927-9.

6 Voortman M, Drent M, Baughman RP. Management of neurosarcoidosis: a clinical challenge. Curr Opin Neurol 2019;32:475-83.

7 Smith $D$, Hänsch H, Bancroft G, et al. T-cell-independent granuloma formation in response to Mycobacterium avium: role of tumour necrosis factor-alpha and interferon-gamma. Immunology 1997:92:413-21.

8 Kunkel SL, Chensue SW, Strieter RM, et al. Cellular and molecular aspects of granulomatous inflammation. Am J Respir Cell Mol Biol 1989;1:439-47.

9 Müller-Quernheim J, Pfeifer S, Männel D, et al. Lung-restricted activation of the alveolar macrophage/monocyte system in pulmonary sarcoidosis. Am Rev Respir Dis 1992;145:187-92.

10 Zissel G, Prasse A, Müller-Quernheim J. Immunologic response of sarcoidosis. Semin Respir Crit Care Med 2010;31:390-403.

11 Pettersen JA, Zochodne DW, Bell RB, et al. Refractory neurosarcoidosis responding to infliximab. Neurology 2002;59:1660.

12 Carter JD, Valeriano J, Vasey FB, et al. Refractory neurosarcoidosis: a dramatic response to infliximab. Am J Med 2004:117:277-9.

13 Sollberger M, Fluri F, Baumann T, et al. Successful treatment of steroid-refractory neurosarcoidosis with infliximab. J Neuro/ 2004:251:760-1.

14 Gelfand JM, Bradshaw MJ, Stern BJ, et al. Infliximab for the treatment of CNS sarcoidosis: a multi-institutional series. Neurology 2017;89:2092-100.

15 Cohen Aubart F, Bouvry D, Galanaud D, et al. Long-Term outcomes of refractory neurosarcoidosis treated with infliximab. J Neurol 2017:264:891-7.

16 Sodhi M, Pearson K, White ES, et al. Infliximab therapy rescues cyclophosphamide failure in severe central nervous system sarcoidosis. Respir Med 2009;103:268-73. 
17 Moravan M, Segal BM. Treatment of CNS sarcoidosis with infliximab and mycophenolate mofetil. Neurology 2009;72:337-40.

18 Santos E, Shaunak S, Renowden S, et al. Treatment of refractory neurosarcoidosis with infliximab. J Neurol Neurosurg Psychiatry 2010;81:241-6.

19 Lord J, Paz Soldan MM, Galli J, et al. Neurosarcoidosis: Iongitudinal experience in a single-center, academic healthcare system. Neurol Neuroimmunol Neuroinflamm 2020;7:e743.

20 Stern BJ, Royal W, Gelfand JM, et al. Definition and consensus diagnostic criteria for neurosarcoidosis: from the neurosarcoidosis Consortium consensus group. JAMA Neurol 2018;75:1546.

21 Fritz D, van de Beek D, Brouwer MC. Clinical features, treatment and outcome in neurosarcoidosis: systematic review and meta-analysis. BMC Neurol 2016;16:220.
22 Lower EE, Broderick JP, Brott TG, et al. Diagnosis and management of neurological sarcoidosis. Arch Intern Med 1997;157:1864-8.

23 Agbogu BN, Stern BJ, Sewell C, et al. Therapeutic considerations in patients with refractory neurosarcoidosis. Arch Neurol 1995;52:875-9.

24 Marangoni S, Argentiero V, Tavolato B. Neurosarcoidosis. Clinical description of 7 cases with a proposal for a new diagnostic strategy. J Neurol 2006:253:488-95.

25 Scott TF, Yandora K, Valeri A, et al. Aggressive therapy for neurosarcoidosis: long-term follow-up of 48 treated patients. Arch Neurol 2007:64:691.

26 Bitoun S, Bouvry D, Borie R, et al. Treatment of neurosarcoidosis: a comparative study of methotrexate and mycophenolate mofetil. Neurology 2016;87:2517-21.

27 Doty JD, Mazur JE, Judson MA. Treatment of corticosteroid-resistant neurosarcoidosis with a short-course cyclophosphamide regimen. Chest 2003;124:2023-6. 